\title{
Information environment of teleworkers in South Africa
}

\author{
H. Nortjé \\ Department of Information Management \\ School of Information Technology \\ Technikon Witwatersrand \\ hnortje@twr.ac.za \\ P.A. van Brakel \\ Department of Information Studies \\ Rand Afrikaans University \\ pavb@rau.ac.za \\ C. Rensleigh \\ Department of Information Studies \\ Rand Afrikaans University \\ cr@rau.ac.za
}

\section{Contents}

1. Introduction

2. Background

3. Methodology

4. Literature review

5. Empirical findings

6. Conclusion

7. References

8. Appendix

\section{Introduction}

The information economy, brought about inter alia by advances in ICT, has led to significant changes in the work environment. Employees are expected to be office workers who are not only computer literate, but information literate as well. The high demand for flexibility has led to a trend that allows workers to perform their duties in locations outside of their traditional workspace. This trend has been named teleworking or telecommuting. This article is based on an investigation of the potential similarities and differences between the information environment of the professional office worker and that of the teleworker. 


\section{Background}

In the industrial age, a clear delineation between work and home was established. Jobs and job roles were clearly defined and management held the 'key' to information in the organization. Information and office were disconnected (information was exchanged only as needed) and employees had to follow instructions and concentrate on their assigned tasks. The physical location of machinery and supplies was necessarily also the place where the work was performed. Workers put in the required time, performed the required tasks and rarely, if ever, felt responsible for the organization's end product. The advances in information technology brought about significant changes in the work environment and led to the creation of the information age.

Mochella (Ruettgers 2000) illustrates the pattern of change in the information and technology field by referring to four overlapping waves. The first wave centred on systems and defined the computer industry of the 1970s. It was a time of centralized information management where only specialists worked directly with computers. The second wave centred on personal computers and began around 1980. It was defined by desktop computing and the growth of local area networks (LANs). The information management in an organization became distributed. In the early 1990s the network wave started rolling; its driving force being the Internet. During this era there was a fusion of computing and communications technologies, and electronic commerce became a reality. We are currently in the thrust of the most significant wave of all, namely the digital information wave.

The significance of this wave is huge because it focuses on content, which is anything that people want to see and hear that can be produced digitally. Information, unlike traditional resources, does not deplete with use, but increases in value when consumption increases. This means that the more information is digitally stored and used, the more it will lead to the creation of new information. This wave is a direct manifestation of the information economy. According to Djoen and Uijttenbroek (1997), the information economy has the following characteristics:

- Accelerated technological developments

- Enhanced information and office intensive activities

- Reduced time-to-market and life cycles of products and services

- Globalization of the market place.

The spiralling supply and demand for information technology drives technological development, which in turn enhances information and office intensive activities. The increase in office intensive activities reduces the life cycle of products and services. Technological advances help organizations to produce and market products and services across geographical boundaries, and an increasing number of organizations view the world as one enormous market. Organizations develop products and services in places where the know-how is available, buy materials and components where they are the cheapest, produce in countries with the lowest labour and distribution costs and sell their products internationally. Organizations must be large enough to compete globally but small enough to respond quickly to local market needs.

All of the changes in the external market of the organization lead to noteworthy internal changes. The trend is towards a flattening of the hierarchical structure in the organization, where management is more centrally located and the responsibility with regard to decisions is spread throughout the organization to every employee. Olmsted and Smith (1997:12) summarize the changes as follows:

'The global economy is a driving force today. It has led to extensive restructuring in most 
organizations as companies have worked to reconfigure themselves and refocus their competencies in order to remain viable in the marketplace. Seeking to become more competitive on a global scale, organisations have looked for ways to become more flexible in order to respond better to fluctuations in demand for products and services.'

The information economy has therefore also influenced the work environment, specifically the duties of workers in an organization. Just as organizations are expected to adapt to the demands of a new global economy, so workers are expected to adapt to the demands of enterprises. In the 1970s and 1980s a typical workday meant going to the office at 08:00 or 08:30 and leaving again at 16:30 or 17:00. Only a select few in middle or top management stayed at the office later or took work home. Few employees had direct access to personal computers and only the specialists were involved in making decisions and using information as a strategic resource. However, the growing developments in the field of ICT have changed the primary tools required by the worker to perform duties from pens, paper, calculators and typewriters to personal computers, telephones and a connection to the Internet via a modem or a network server.

Apart from being expected to be computer literate, workers are increasingly expected to be information literate. All employees are expected to know the 'where' and 'how' of finding information, using and modifying information, storing information and allowing the relevant people in the organization access to information. The fact that a customer has so many options when purchasing a product or requiring a service means that the relationship between the organization and its customers is central to success. Customers tend not to care where, when or how their needs are met as long as the resolution is swift, responsive and predictable. Organizations and workers must be flexible and are required to adjust quickly to new demands. In line with this required flexibility, there is a growing need to spend time more productively. This has led to a trend that allows workers to perform their duties in locations outside of their traditional workspace, namely by teleworking. Teleworking necessitates a transition from in-person supervision to remote managing, from face-to-face communication to technology-assisted communication and from on-site working to off-site working.

Nilles (1998:1) is said to have coined the term 'telecommuting' or 'teleworking' approximately 25 years ago while stuck in traffic in Los Angeles. The original interest in teleworking was therefore driven by concerns about traffic congestion and pollution. In the 1980s, as companies focused increasingly on cutting costs, they pointed to teleworking as a means of reducing the expense of maintaining office space. More recently, organizations have begun to view teleworking as a tool to attract and retain top personnel in fields with short labour supplies. Over the years, the number of alternative work forms has increased and now include terminology such as satellite centres, neighbourhood work centres and mobile working. The focus of this research was therefore on teleworking as manifested in a 'work from home' situation. The concept of 'teleworking' developed parallel with the developments in ICT. It is therefore necessary to briefly discuss these developments.

In the 1980s, the cost of computers decreased to such an extent that workers were no longer forced to access remote, shared host computers and printers, but could use microcomputers or the so-called personal computer or desktops. New software emerged, allowing the computerization of, for example, spreadsheets and graphic design. Communication software tools enabled personal computers to imitate terminals and access central applications that were installed on host computers. These software tools also enabled the linking of personal computers in local area networks, thus enabling workers to create and share information. Towards the end of the decade, the development of smaller, portable laptop computers made it easier for workers to link to the host computer at work while staying at home. However, the limited bandwidth of telephone lines was a problem that directly influenced the growth of 
teleworking in this decade.

In the 1990s, computers became more powerful and data communication links within and between workplaces had enough bandwidth to enable the development of multimedia-bound architecture. Access to multimedia content was now possible through the Internet and the World-Wide Web (Web). ICT infrastructures became more cost effective and the sharing of information became as easy as sending an e-mail. According to Fitzer (1997:67), the popularity of teleworking grew owing to several factors, the most important of which was the technological advances as discussed. Other factors included:

- Cost saving

- Productivity

- Valuable skills

- Fostering diversity

- Employee needs

- Productivity concerns.

A study of the literature indicated that although there were numerous advantages relating to teleworking, there were also some concerns, such as the accessibility of information by teleworkers in particular. Pliskin (1997:170) says that despite all the dramatic advancement of information technology in recent years, the virtual proximity of information resources has been short-ended. Even when top performing desktop computers and state-of-the-art modems are used at home or on the road, accessing an organization's intranet is not always permitted for security reasons. Also, teleworkers are still limited in their ability to manipulate multimedia content and to download large multimedia files via normal telephone lines.

From this background information, it seems that the information infrastructure made available to teleworkers may lack adequate access to essential information and information sources. The information environment of the teleworker may therefore be different from that of the office or office worker. (The term office worker will be used, meaning an employee also involved in office sharing.) A study of the literature presented almost no information relating to teleworking in the South African context and the hypothesis was that there would be very few organizations in the country that were involved in formal teleworking programmes. The empirical component of the study was therefore an investigation of the South African teleworking environment and an attempt to identify the differences and similarities between the information environment of an office worker and an employee in an alternative work situation such as teleworking. The research focussed on the following components:

- The information environment of the traditional or office worker

- The unique features of the information environment of the teleworker in South Africa.

\section{Methodology}

As mentioned earlier, a literature search relating to teleworking in South Africa yielded almost nothing. The research was therefore based on a literature study consisting of reports, articles and other publications originating mostly in Europe and the USA. Contact was established with certain authors who had been researching this field. Their experiences are incorporated into this article. The literature study culminated in research that provided theoretical and, where possible, practical information on teleworking. 
had formal policies and strategies with regard to teleworking. People in the human resource departments of organizations were contacted via telephone calls and e-mails. Where relevant, people from other sections in the organization were approached as well. None of the organizations that were contacted had full-scale teleworking sections or departments. The teleworkers who were identified were engaged in teleworking on an ad hoc basis and had no written agreement with their organizations.

Large organizations in Gauteng were contacted, because this province is widely regarded as the economic hub of South Africa and most of the major organizations' head offices are located in Johannesburg, Midrand or Pretoria. The banking sector was targeted first because previous research conducted within the South African context indicated that some of the major banks might be implementing teleworking programmes (Hoffman 2002). Several senior people from the human resource departments of major banks were contacted, but no information with regard to any teleworking activities was found. One bank mentioned that it was in the investigating phase with regard to teleworking, but had not done any real planning or implementation.

It was then decided to target organizations that were known to be on the forefront of innovative ideas and activities. One such sector was the consulting industry. These organizations were generally very unhelpful and it was impossible to establish whether any of them had teleworking programmes. One indicated that it did have teleworkers, but said that it had a policy not to assist in any research outside of the organization.

The information and communications technology industry was consequently targeted and almost identical responses were received. None had any formal teleworking programmes, but it was discovered that one large international company did have a number of employees involved in ad hoc teleworking. At this point, it became clear that teleworking was a very new and unknown concept in South Africa. It was therefore impossible to target a specific industry or even a specific organization and it was decided to target individuals. These individuals were found by sending out e-mail messages and making telephone calls. Interviews were eventually conducted with eight people, who were all full-time, professional employees at different organizations (see Appendix 1 for the interview questionnaire).

Although the respondents originated from different organizations and different industries within South Africa, most of them were found to be linked to the ICT industry. A possible reason for this is the fact that ICT is the enabler of the teleworking concept, as has been mentioned earlier. Another reason could be the changing and innovative nature of this industry, which enables organizations to adopt and accept new ideas more easily and quickly. The respondents were therefore selected only because they were full-time employees and were working from a remote location or home office - even on an ad hoc basis.

\section{Literature review}

\subsection{Information environment of the office worker}

Increasingly, organizations are approaching information as a strategic resource that should be managed. Therefore, office workers are expected to be both computer literate and information literate. This implies that they must know where to find information and how to use, modify, store and allow access to it. Office workers are therefore expected to act as information specialists as well as to be competent in their chosen professions. The ability of an office worker or organization to accomplish any given task or reach any desired goal is directly related to the ability to find the right information at the right time. Employees are typically involved in the business processes of an organization and are therefore required to 
manage their personal information. The tasks of office workers are broadly divided into four main categories: managing documents, communicating, managing information and decisionmaking. Difference information systems are used for each of these different tasks in an organization.

\subsubsection{Managing documents}

Internal documents, such as reports, manuals, brochures and memos, are common mediums for storing and packaging organizational data and information. Documents have structure and context, and they include enough information to be usable (Davenport 1997:146). Managing documents in an office environment includes document creation, storage, retrieval and dissemination or sharing. Documents in an organization are increasingly produced electronically through the use of information technology, which includes software such as word processing, desktop publishing, Web publishing and work-flow managers. Most word processing software has advance features, such as spelling, grammar, style and thesaurus checkers, that enable the users to automate writing tasks and merge functions that link letters or other documents with names and addresses in a mailing list. The more recent word processing software enables users to create and access Web pages.

Desktop publishing uses the basic features of word processing and combines them with design elements, such as graphics and special layout features, to create a quality document that is ready to publish (Long and Long 2002:53). Document imaging systems are systems that convert paper documents and images into digital format so that they can be stored and accessed via computer (Laudon and Laudon 2001:438). These systems store, retrieve and manipulate a digitized image of the document, permitting the document itself to be archived and/or discarded.

\subsubsection{Employee communication}

Communication is necessary, first, to achieve coordinated actions and, second, to allow for the sharing of information. There is a close link between communication and coordination as the one is impossible without the other. The majority of organizations today organize their workforce in groups or teams (Moorehead and Griffin 1998:290). Members of these teams rely on each other to execute tasks efficiently with proper coordination as a key success factor for teams operating in organizations. Scheduling and coordinating tasks and meetings between team members are therefore important aspects of an office worker's day-to-day functions.

Group collaboration systems that support the functioning of groups play a key role in organizations today (Lucas 2000:570). These systems, called groupware, have powerful capabilities that allow employees to schedule, communicate and share resources, using information and communication technology. One aspect of group collaboration systems that pertains to scheduling is networked digital calendars. These calendars enable team members to view each other's daily as well as project schedules. In addition to groupware, there is a massive amount of ICT available today, including fax machines, e-mail, voice mail, digital answering services, videoconferencing, intranets, portals, and more. These systems are called communications systems and are defined as the communication of information by electronic means, usually over some distance (Beekman 2001:492).

\subsubsection{Managing information}

In the information economy, information is the lifeblood of every organization and it must be properly managed to retain its value for the organization. At some point, almost every office worker is involved in the process of managing information because information is constantly generated in every action and aspect of the organization. Some of this information is formal and structured, such as invoices, personnel records and bank records, while a certain amount of it is unstructured or informal, such as customer feedback (Watson 1996:505). It is only in 
recent years that organizations began to focus on capturing unstructured information, leading to the development of new technologies, such as customer relationship management

software.

In many of the larger organizations, there is a formal data administration function that is responsible for managing corporate information. The fundamental principle of data administration is that all information is the property of the organization as a whole and cannot belong to any one business unit or function in the organization (Laudon and Laudon 2001:250). Organizational information should be available to any employee who may need it to perform a task. This has led to the development of systems that control all the information in an organization. Most of the organizational information is contained in database systems. Typical data management technology includes database management systems and spreadsheets (Capron and Johnson 2002:416).

A database management system consists of hardware and software that are used to define, create, retrieve, manage and protect information within the database (Watson 1996:506). According to Capron and Johnson (2002:416), employees are mostly involved in using the databases for data maintenance and data retrieval. Electronic spreadsheets enable the user to manipulate numeric and quantitative information and perform tasks, such as repetitive calculations, budgeting, investment management, business projections and scientific simulations (Beekman 2001:152).

\subsubsection{Decision-making}

Decision-making can be classified according to organizational levels. Lucas (2000:35) suggests the following types of decisions:

- Strategic decision-making. This type of decision-making determines the objectives, resources and policies of the organization.

- Managerial control decision-making. Decision-making at this level is principally concerned with how effectively and efficiently resources in the organization are being utilized.

- Office-level decision-making. Decisions of this type deal with evaluating new ideas for products and services,. It is also concerned with ways in which to distribute information throughout the organization.

- Operational control decisions. An operational control decision covers the day-to-day problems that affect the organization.

In addition, Lucas (2000:560) defines decision support systems as computer-based systems that use information, models and simulation to help the decision-maker solve unstructured problems. Decision support systems are interactive; employees enter certain variables and rely on the system to produce certain outputs. Changing the input variables will result in a different set of outputs. Thus, through simulation, decision support systems assist with the process of making decisions. In Table 1 there is a summary of the features of the information environment of office workers.

Table 1. Factors that influence the information environment of the office worker

\begin{tabular}{|l|l|}
\hline \multicolumn{1}{|c|}{ TASK } & \multicolumn{1}{|c|}{ INFORMATION SYSTEM } \\
\hline $\begin{array}{l}\text { Managing documents } \\
\text { (Creation, storage, retrieval, } \\
\text { dissemination) }\end{array}$ & $\begin{array}{l}\text { Word processing } \\
\text { Desktop publishing } \\
\text { Document imaging systems }\end{array}$ \\
\hline & $\begin{array}{l}\text { Networks } \\
\text { (Internet, intranet/extranet) }\end{array}$
\end{tabular}




\begin{tabular}{|l|l|}
$\begin{array}{l}\text { Communication } \\
\text { (Individual, group, team) }\end{array}$ & $\begin{array}{l}\text { Communications } \\
\text { (Faxes, modems, voice mail, e-mail, } \\
\text { videoconferencing, cellular phones, } \\
\text { personal digital assistants, groupware, etc.) }\end{array}$ \\
\hline $\begin{array}{l}\text { Managing information } \\
\text { (Formal information, informal } \\
\text { information) }\end{array}$ & $\begin{array}{l}\text { Spreadsheets } \\
\text { Database management systems }\end{array}$ \\
\hline $\begin{array}{l}\text { Decision-making } \\
\text { (Strategic, managerial, office, operational) }\end{array}$ & Decision support systems \\
\hline
\end{tabular}

\subsection{Information environment of the teleworker}

Using Table 1 as a framework, a literature study was undertaken in an effort to establish the features of the information environment of the teleworker. Features that were identified included information systems, communications and security. In this regard, no references were found on teleworking in context with tasks such as managing documents, decisionmaking, utilizing information or addressing information overload. Information systems are designed to meet the operational and functional needs of an organization. Access to appropriate systems is crucial for employees to perform their jobs successfully.

It is apparent from the literature that there are no hard and fast rules with regard to the types of information systems and ICT a teleworker should use. Some teleworkers may need only a single telephone connection, while others may need high-speed connections with state of the art computers. Simmons (1996:100) stated as early as 1996 that the same hardware that is used in the office is required by the teleworker at his or her home office. Hoffmann (2002) says that most teleworkers typically choose portable computers, such as laptops and notebooks, because of their convenience. The teleworker is able to store his or her information on a portable computer, then move it to the office and have instant access to the stored information. Portable computers currently on sale include all the necessary peripherals, such as printers, fax or data modems and network cards. The specifications of the computer, printer, scanner and other peripherals depend on the teleworker's requirements, and differ from person to person.

Nilles (1998:74) describes networks as the 'arteries' of teleworking. Networks are enabled by communications equipment and are therefore a vital part of the information environment of the teleworker. Different types of networks exist, namely local area networks (LANs), metropolitan networks (MANs), wide area networks (WANs), global area networks (GANs) and virtual area networks (VANs) (Turban, Rainer and Potter 2001:186). Of the vast array of communications media available, the following are specifically mentioned in relation to teleworking (Hoffmann 2002):

- Electronic mail (e-mail)

- Videoconferencing

- Teleconferencing

- Cellular telephones

- Voice mail.

It is apparent that information security is one of the major issues facing organizations with regard to teleworking (York 1999:4). It is relatively easy to safeguard organizational and private information when it is kept on the organization's servers with no access from outsiders. However, protecting organizational information in today's networked environment is not always easy. Wolk (2000) recommends at least three levels of personal security, namely anti-virus software, a personal firewall system for the teleworker and encryption of valuable data. Organizations can also consider the implementation and enforcement of 
security policies for teleworking. A security policy provides clear guidelines with regard to the legitimate use of equipment and its physical protection (Chen 2000:69).

top

\section{Empirical findings}

As mentioned earlier, the purpose of the empirical research was to investigate the information environment of teleworkers in South Africa. It was found that teleworking in South Africa seemed informal and occurred much less frequently than was assumed. A possible reason could have been that the structure and culture of organizations in South Africa were still traditional and too rigid and were therefore not well suited to teleworking.

While it was established that teleworkers might experience problems with regard to accessing appropriate information systems and sources, it seemed, however, that teleworkers in South Africa did not experience these anticipated problems. A possible explanation could be that problems were addressed as they occurred because of the ad hoc nature of the teleworking agreements. This means that the drain on organizations' information resources was limited and the impact was therefore not causing any problems.

A framework was created in an effort to identify the features of the information environment of the office worker, as summarised in Table 1. This summary was used as a basis for the empirical component of the study. An analysis of the results of the interviews revealed differences between the office worker and the teleworker, as described below.

\subsection{Storing, retrieving and sharing documents}

Teleworkers were involved in the task of managing documents, managing information, decision-making and communicating. When it came to creating documents, teleworkers used the same information systems as office workers. A distinction could, however, be made with regard to the storage, retrieval and sharing of documents. The respondents indicated that they stored documents on the hard drives of their computers and on the servers of the organization. Almost none of them were making use of paper-based storage methods. This was contrary to the traditional office of the office worker, where large amounts of information were stored in paper-based form. The differences of storing documents also related to a difference between retrieving and sharing documents. When retrieving documents, teleworkers used electronic means exclusively. The same applied to the dissemination of documents, which was done mostly by using e-mail and other electronic methods.

\subsection{Communication media}

Managing information entailed the same processes for the teleworker as for the office worker. Data management systems were used on a daily basis and the organizational databases seemed to be the preferred method for maintaining, updating and retrieving information. Teleworkers relied heavily on e-mail, cell phones and telephones for their communication needs and occasionally also made use of fax machines. It is important to note that the use of video and teleconferencing was not as widespread as it was in the information environment of the office worker. The teleworkers indicated that they did not view these communication mediums as crucial to their functioning as employees.

All the teleworkers who were interviewed were involved in team or group work. They said that they preferred face-to-face meetings as a means of communication with team members, especially at the commencement of a project. Communicating with team members was generally not a problem but some of them indicated that from time to time they did need to gather information from team members and therefore it would be easier if they were in the 
same location. Most of the teleworkers also relied on groupware or electronic team rooms as a medium for communication. All project information, communications and updates were stored in the electronic team room and were accessible to team members. When the communication methods of teleworkers were compared to those of office workers, it was clear that a distinction could be made with regard to electronic and paper-based communication. Almost none of the teleworkers were using paper-based communications, such as letters and memorandums. Generally, they relied far more on communicating electronically.

\subsection{Decision-making}

When it came to decision-making, teleworkers were mainly involved in operational and office-level decisions. As mentioned earlier, operational decisions involve solving day-today problems and office-level decisions on the evaluation and creation of new ideas, products and services. Only some of the respondents participated in decisions on a managerial and strategic level. Middle and senior management were mostly involved in managerial and strategic decisions. It therefore appeared that very few senior managers were involved in teleworking and that it was mostly supervisory and middle management employees who made up this staff component. None of the teleworkers used decision support systems, thus distinguishing them from office workers who do.

\subsection{Information sources}

Most of the teleworkers were linked to their organization's network via a standard 56K, dialup connection. Very few used an ISDN 128K line with a permanent connection. These connections formed the basis for the teleworkers' access to their organization's information resources. All the teleworkers pointed out that their organization's intranet was their major source of information; it seemed that their organizational intranets contained almost all the information that the teleworkers needed. Technical reports, information on procedures and policies, organizational research and project information or on-line databases were accessed via the intranet. Teleworkers also used the communications technology to access Web sites on the Internet, where they gathered information concerning the organization, competitors, clients and the industry wherein they functioned. Electronic journals, white papers and articles were also accessed via the Internet. Not many of the organizations had an extranet, but a few of the teleworkers did say that they have access to the extranet and used it to obtain information relating to their business partners.

Respondents also used on-line user forums as information sources because these were easily accessible and provided pertinent information about their specific field or industry. The use of paper-based information sources was very limited among teleworkers. Trade journals and reference manuals were sometimes used but the use of magazines and newspapers was almost non-existent. It is evident that the earlier trend continues because teleworkers were much more reliant on electronic information sources than on paper-based sources. They also said that they were fairly satisfied with the availability of these sources and overall they seemed to have adequate access to these information sources.

\subsection{Equipment}

Generally the teleworkers needed a portable computer, modem and a telephone line to do their work. All of them indicated that they did have the needed equipment and that it was the property of their organization. The organizations were mostly responsible for replacing stolen equipment and for upgrading outdated equipment. Although not formally in writing, teleworkers generally understood that they were governed by the same policies and procedures as the rest of the organization when it came to the use of equipment. They all agreed that their organizations did not actively control this issue. 
Interestingly enough, security, both physical and within information systems, did not seem to be a major concern to the organization or the teleworkers. Very few of the teleworkers were aware of any special security features and the ones who were said that it did not influence their work in any way. Standard security measures included anti-virus software, and normal login names and passwords were required on most networks.

\subsection{Information overload}

Information overload appeared to be a much greater problem for teleworkers than it was for office workers. The majority of teleworkers indicated that they were suffering from information overload and that the remoteness or isolation of their working environment magnified this problem.

\section{Conclusion}

The information environment of the office worker revealed certain distinct features, such as the manner in which documents and information were managed and the systems being used. These features were compared to the information environment of the teleworker through an investigation of teleworkers in South Africa.

Although very few South African organizations were involved in formal teleworking programmes, it was possible to establish certain trends through employees who had an ad hoc arrangement with their organizations. In conclusion, it was found that the information environment of the teleworker was similar to that of the office worker but certain distinctions also came to the fore. The findings of the research can therefore be summarized as follows:

- Teleworking was an extremely new concept in South Africa and there were very few organizations currently embracing this concept. Policies and procedures for formal teleworking were non-existent and teleworking was therefore an ad hoc arrangement between some employees and their organizations.

- Teleworking was largely restricted to professional employees at supervisory and middle management level.

- Teleworkers were part of formal project teams and derived from the segment of employees that worked on their own.

- Teleworking was not possible without the use of communications technology. Teleworkers operated within the electronic environment and had to be connected to the organization's network to function successfully.

- Teleworkers indicated that they were able to access the required information easily.

- Security appeared not to be a major concern for organizations or teleworkers.

The information environment of the office worker and that of the teleworker was very similar and it should therefore be fairly easy for organizations and employees to make the transition and adopt the concept of teleworking.

\section{References}

Beekman, G. 2001. Computer confluence exploring tomorrow's technology. New Jersey: Prentice-Hall.

Capron, H.L. and Johnson, J.A. 2002. Computers: tools for an information age. New Jersey: Pearson Education. 
Chen, A. 2000. Wolves at the door. eWeek 17(49):69-73.

Davenport, T.H. 1997. Information ecology: mastering the information and office environment. New York: Oxford University.

Djoen, S. and Uijttenbroek, A.A. 1997. Information infrastructure management. Information systems management 14(4):33-42.

Fitzer, M.M. 1997. Managing from afar: performance and rewards in a telecommuting environment. Compensation \& benefits review 29(1):65-73.

Hoffmann, E. 2002. Information technology, virtual offices and telework. South African journal of information management 4(2). [Online]. Available WWW:

http://www.rau.ac.za/infosci/raujournal. [Accessed 16 July 2002].

Laudon, K.C. and Laudon, J.P. 2001. Management information systems. New Jersey: Prentice Hall.

Long, L. and Long, N. 2002. Computers: information technology in perspective. New Jersey: Prentice-Hall.

Lucas, H.C. 2000. Information technology for management. New York: Irwin McGraw-Hill.

Moorehead, G. and Griffin, R.W. 1998. Managing people and organisations. Boston: Houghton Mifflin.

Nilles, J. 1998. Managing telework: strategies for managing the virtual workforce. New York: John Wiley.

Olmsted, B. and Smith, S. 1997. Managing in a flexible workplace. New York: AMACOM.

Pliskin, N. 1997. The telecommuting paradox. Information technology \& people, 10(2):164172.

Ruettgers, M. 2000. Opportunity and upheaval ahead. Vital speeches of the day, 66(17):531333. [Online]. Available WWW: http://search.global.epnet. [Accessed on 18 March 2001].

Simmons, S. 1996. Flexible working: a strategic guide to successful implementation and operation. London: Kogan Page.

Turban, E., Rainer, R.K. and Potter, R.E. 2001. Introduction to information technology. New York: John Wiley.

Watson, R.T. 1996. Data management: an organizational perspective. New York: John Wiley.

Wolk, M. 2000. Telecommuting - a security threat? [Online]. Available WWW: http://www.zdnet.com. [Accessed 3 April 2001]

York, T. 1999. Telecommuting trials. InfoWorld. [Online]. Available WWW: http://www.findarticles.com. [Accessed 18 March 2001]. 


\section{Appendix 1}

\section{Section 1}

a) To what extent are you involved in the following on a daily basis?

\begin{tabular}{|l|c|c|c|c|}
\hline Creating documents & 1 Not at all & 2 & 3 & $\begin{array}{c}4 \text { To a large } \\
\text { extent }\end{array}$ \\
\hline Storing documents & 1 Not at all & 2 & 3 & $\begin{array}{c}4 \text { To a large } \\
\text { extent }\end{array}$ \\
\hline Retrieving documents & 1 Not at all & 2 & 3 & $\begin{array}{c}4 \text { To a large } \\
\text { extent }\end{array}$ \\
\hline Disseminating documents & 1 Not at all & 2 & 3 & $\begin{array}{c}4 \text { To a large } \\
\text { extent }\end{array}$ \\
\hline
\end{tabular}

b) What does the following involve?

\begin{tabular}{|l|l|}
\hline Creating documents & \\
\hline Storing documents & \\
\hline Retrieving documents & \\
\hline Disseminating documents & \\
\hline
\end{tabular}

c) Which one of the following communication systems do you use and what do you use it for?

\begin{tabular}{|l|l|l|}
\hline & \multicolumn{1}{|c|}{ Use } & Reason \\
\hline Telephone & & \\
\hline Cell phone & & \\
\hline Teleconferencing & & \\
\hline Fax & & \\
\hline E-mail & & \\
\hline Videoconferencing & & \\
\hline Memos & & \\
\hline Letters & & \\
\hline Other & & \\
\hline
\end{tabular}

d) Are you involved in team or group work? If so, what is your preferred type of communication with team or group members? Please provide reasons.

e) Please rank the frequency of the type of decisions that you must make from 1 to 4 , with 1 being the least and 4 being the most frequent.

Strategic decisions (determining organization objectives and policies)

Managerial decisions (effective and efficient use of resources)

Knowledge level (evaluation of new ideas, products etc.) 
Operational level (day-to-day problems)

f) What type of information do you need to make decisions?

g) How do you access this information?

h) Do you use decision support systems?

i) What other tasks do you perform?

j) What information do you require to complete these tasks?

k) How do you access this information?

l) Which one of the following information sources do you use, how do you use it and what do you use it for?

\begin{tabular}{|l|l|l|l|}
\hline \multicolumn{1}{|c|}{ Paper based } & Use & How & Reasons \\
\hline Books & & & \\
\hline $\begin{array}{l}\text { Reference material } \\
\text { (dictionaries, } \\
\text { encyclopaedias) }\end{array}$ & & & \\
\hline $\begin{array}{l}\text { Periodicals } \\
\text { journals) }\end{array}$ & & & \\
\hline $\begin{array}{l}\text { Company research } \\
\text { and technical reports }\end{array}$ & & & \\
\hline $\begin{array}{l}\text { Magazines and } \\
\text { newspapers }\end{array}$ & & & \\
\hline Other & & & \\
\hline
\end{tabular}

\begin{tabular}{|l|l|l|l|}
\hline Electronic sources & Use & How & Reasons \\
\hline CD-ROM & & & \\
\hline Company databases & & & \\
\hline Own databases & & & \\
\hline On-line databases & & & \\
\hline Web sites & & & \\
\hline Newsgroups & & & \\
\hline Listservs & & & \\
\hline Intranet & & & \\
\hline Extranet & & & \\
\hline
\end{tabular}

m) What other information do you require that you do not currently have access to?

\section{Section 2}

a) Do you use word processing software, such as Microsoft Word?

\begin{tabular}{|l|l|l|l|}
\hline 1 Not at all & 2 & 3 & 4 To a large extent \\
\hline
\end{tabular}

b) What do you use it for?

c) Do you use desktop publishing software, such as Quark Express? 
d) What do you use it for?

e) Do you use document imaging systems such as scanners?

\begin{tabular}{|l|l|l|l|}
\hline 1 Not at all & 2 & 3 & 4 To a large extent \\
\hline
\end{tabular}

f) What do you use it for?

g) Do you use data management systems such as spreadsheets or databases?

\begin{tabular}{|l|l|l|l|}
\hline 1 Not at all & 2 & 3 & 4 To a large extent \\
\hline
\end{tabular}

h) What do you use them for?

i) Does your organization make use of a wide area network (WAN) or a value added network (VAN)?

j) Do you have access to the Internet? If so, how are you connected (line type, speed, etc.)?

k) Do you have access to the organization's intranet and/or extranet? If so, is it a permanent connection?

\section{Section 3}

a) What is the minimum equipment (hardware) that you require to perform your job at home? Do you have all the necessary equipment?

b) Does the equipment in your home office belong to you or to the organization?

c) Who is responsible for replacing equipment in the case of theft and for upgrading it?

d) Did the organization specify any special physical security features for your home office?

e) Are you aware of any special security features built into the information systems that you are using, such as firewalls and special encryption? If so, do these features impact on your ability to manage information?

f) Are you restricted by your organization with regards to how and for what purpose you use the information technology equipment?

g) Does information overload influence the performance of your job?

What additional aspects do you think influences the way you manage information and perform your job? How do they influence it?

\section{Disclaimer}

Articles published in SAJIM are the opinions of the authors and do not necessarily reflect the opinion of the Editor, Board, Publisher, Webmaster 
or the Rand Afrikaans University. The user hereby waives any claim he/she/they may have or acquire against the publisher, its suppliers, licensees and sub licensees and indemnifies all said persons from any claims, lawsuits, proceedings, costs, special, incidental, consequential or indirect damages, including damages for loss of profits, loss of business or downtime arising out of or relating to the user's use of the Website.

ISSN 1560-683X

Published by InterWord Communications for the Centre for Research in Web-based Applications, Rand Afrikaans University 